RESEARCH

\title{
circAkap17b acts as a miR-7 family molecular sponge to regulate FSH secretion in rat pituitary cells
}

\author{
Chang-Jiang Wang*, Fei Gao*, Yi-Jie Huang, Dong-Xu Han, Yi Zheng, Wen-Hua Wang, Hao Jiang, Yan Gao, Bao Yuan $\mathbb{D}$ \\ and Jia-Bao Zhang \\ Department of Laboratory Animals, Jilin Provincial Key Laboratory of Animal Model, Jilin University, Changchun, Jilin, China
}

Correspondence should be addressed to B Yuan or J-B Zhang: yuan_bao@jlu.edu.cn or zjb@jlu.edu.com

*(C-J Wang and F Gao contributed equally to this work)

\begin{abstract}
The pituitary gland functions as a prominent regulator of diverse physiologic processes by secreting multiple hormones. Circular RNAs (circRNAs) are an emerging novel type of endogenous noncoding RNA that have recently been recognized as powerful regulators participating in various biological processes. However, the physiological roles and molecular mechanisms of circRNAs in pituitary remain largely unclear. Herein, we concentrated on expounding the biological function and molecular mechanism of circRNA in rat pituitary. In this study, we identified a novel circRNA in pituitary tissue, circAkap17b, which was pituitary- and stage-specific. Then, we designed circAkap17b siRNA and constructed an overexpression plasmid to evaluate the effect of loss- and gain-of-circAkap17b function on FSH secretion. Interestingly, silencing circAkakp17b significantly inhibited FSH expression and secretion, while overexpression of circAkap17b enhanced FSH expression and secretion. Furthermore, dual luciferase reporter and RNA immunoprecipitation (RIP) assays confirmed that circAkap17b could serve as miR-7 sponge to regulate target genes. Additionally, miR-7b suppressed FSH expression and secretion by directly targeting Fshb through the dual luciferase reporter and RT-qPCR analysis. Additionally, rescue experiments showed that circAkap17b could regulate FSH secretion in pituitary cells through a circAkap17b-miR-7-Fshb axis. Collectively, we demonstrated that circAkap17b could act as a molecular sponge of miR-7 to upregulate expression of the target gene Fshb and facilitate FSH secretion. These findings provide evidence for a novel regulatory role of circRNAs in pituitary.
\end{abstract}

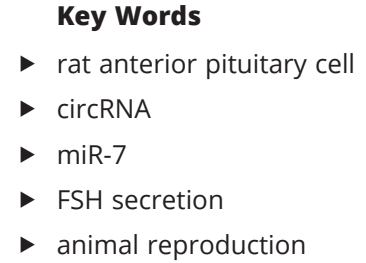

Journal of Molecular Endocrinology (2020) 65, 135-148

\section{Introduction}

The pituitary gland, as the most important endocrine organ secreting hormones essential for homeostasis, is composed of the adenohypophysis and neurohypophysis and plays a critical role in regulating diverse physiological progression (Fauquier et al. 2002, Hong et al. 2016).
Follicle-stimulating hormone (FSH) is synthesized and secreted by the adenohypophyseal portion (Sheng et al. 2018), which contributes to modulating reproductive and development. In females, FSH induces follicular growth and maturation and contributes to LH-triggered ovulation 
and luteinization (Howles 2000, McGee \& Hsueh 2000). In males, FSH stimulates proliferation, development, and maturation of Sertoli cells and accelerates the secretion of androgen-binding protein, inducing and maintaining normal sperm production (Simoni et al. 1999). Furthermore, FSH can directly regulate bone mass, and blocking FSH can not only prevent bone loss, but also reduce body fat accumulation and maintain energy homeostasis (Sun et al. 2006, Liu et al.2017). Consequently, it is crucial to further address the molecular mechanisms involved in FSH regulation.

Circular RNAs (circRNAs), a novel class of noncoding RNAs, have attracted great research interest and become an important research field in recent years (Qu et al. 2015). However, circRNAs were once thought to be by-products of abnormal RNA splicing errors in the process of gene transcription (Cocquerelle et al. 1993, Hentze \& Preiss 2013) until the rapid development of next-generation sequencing technology and bioinformatics analysis, which have transformed circRNAs from waste to treasure (Dong et al. 2017, Guo et al. 2017). In contrast to linear mRNA, circRNAs are characterized by a special covalently closed continuous loop structure with neither a $5^{\prime}$ cap nor a 3' polyadenylated tail (Chen \& Yang 2015, Qu et al. 2015). Due to their cyclization specificity, circRNAs are highly stable, conserved across species, preferentially distributed in the cytoplasm, and show a characteristic tissue or developmental stage-specific pattern (Jeck et al. 2013, Chen 2016). There is accumulating evidence that circRNAs are involved in various physiological processes such as myogenesis and differentiation (Legnini et al. 2017, Li et al. 2019b,c), mammary development and milk synthesis (Liu et al. 2019d), proliferation (Zhou et al. 2019), apoptosis (Guo et al. 2019b), cardiac fibrosis (Zhu et al. 2019), oxidative stress, and inflammation (Chen et al. 2019a). Furthermore, the occurrence of disease is closely associate with the aberrant expression of some circRNAs (Dube et al. 2019, Garikipati et al. 2019, Guo et al. 2019a, Huang et al. 2019a, Liu et al. 2019a, Tian et al. 2019, Wu et al. 2019a). Notably in cancers, circRNAs can act as the sponge of miRNAs to affect tumor pathological progression by inhibiting cancer cell proliferation, metastasis, invasion, and epithelial-mesenchymal transition (EMT) (Chen et al. 2018, Huang et al. 2019b, Su et al. 2019, Xue et al. 2019, Yuan et al. 2019, Zhang et al. 2019a,b, Zhen et al. 2019). In addition to a competing endogenous RNA (ceRNA) mechanism, circRNAs can interact with RNAbinding proteins to regulate gene expression, and some circRNAs can encode extraordinary proteins (Legnini et al. 2017, Yang et al. 2017b,c, Wu et al. 2018).
miR-7, with a high degree of pituitary specificity (Amar et al. 2012, He et al. 2018, Wang et al. 2019a), plays a vital role in regulating diverse biological processes such as insulin signaling (Fernandez-de Frutos et al. 2019), neuronal processes (Hu et al. 2019), diet-induced obesity (Gao et al. 2019), EMT, trophoblast invasion (Shih et al. 2019), hormone secretion, and hypogonadism (Ahmed et al. 2017, Zhang et al. 2017a, Wang et al. 2019a). In our previous study, we analyzed the expression profiles of circRNA between mature and homologous immature rat pituitary tissue samples (Han et al. 2019). Based on nextgeneration sequencing with circRNA and bioinformatics, we constructded circRNA-miRNA-mRNA networks in the rat anterior pituitary. We further predicted and screened differentially expressed rno_circ_0004036 that may act as potential miRNA molecules to regulate rat $F$ shb expression. However, the role and mechanism of circRNAs in the rat pituitary have not been comprehensively defined.

In this study, rno_circ_004036, designated circAkap17b, was initially identified based on a previous study and bioinformatics. Subsequently, we explored whether circAkap17b could regulate FSH secretion by sponging miR-7 through a series of RT-qPCR, RIP, FISH, and luciferase reporter functional assays. Our results were expected to elucidate potential biological functions of circRNA in the rat pituitary gland and enrich research on the regulation of hormones by ncRNA.

\section{Materials and methods}

\section{Ethics statement}

The experiment was carried out in strict accordance with the recommendations of the Guide for the Care and Use of Laboratory Animals of Jilin University. All rats were fed in the Jilin Provincial Key Laboratory of Animal Model. Animals had free access to food and water that had been disinfected and sterilized. They were housed in a capacious and comfortable room with a $12 \mathrm{~h}$ light: $12 \mathrm{~h}$ darkness cycle. Animals were euthanized through inhalation of superfluous carbon dioxide without pain and suffering. Animal carcasses were treated harmlessly after completion of the experiments.

This study was approved by the Institutional Animal Care and Use Committee of Jilin University (Permit Number: SY201901010).

\section{Animals and cell lines and culture}

Sprague-Dawley (SD) rats were purchased from ChangSheng (Liaoning) with a production license and 
quality certificate. The 6-month-old pituitaries of male rat were used for primary cell culture. The pituitary adenomas cell lines (MMQ, GH3) were obtained from the National Infrastructure of Cell Line Resource (Resource number: 3111C0001CCC000008, 3111C0001CCC000081). In addition, the cultured H9C2 cell line (rat) was used in the RIP experiment. All primary cell and adenomas cell lines were cultured at $37^{\circ} \mathrm{C}$ in a $5 \% \mathrm{CO}_{2}$ atmosphere.

The culture method for rat primary pituitary cells has been clearly described in our previous study (Jeck et al. 2013).

\section{Total RNA and gDNA extraction}

Total RNA was isolated using TRIzol reagent (Invitrogen), and gDNA was extracted using the Genomic DNA Isolation Kit (Sangon Biotech, Changchun, China) according to the manufacturer's recommended protocol.

\section{Nucleic acid preparation and qRT-PCR}

cDNA was synthesized using the FastQuant RT Reagent Kit with a gDNA wiper (Tiangen Beijing, China). For PCR, we used PCR Master Mix (2x) (Thermo Fisher Scientific), and the cDNA and gDNA PCR amplification products were examined using $2 \%$ agarose gel electrophoresis. The DNA marker used was DL2000 (Vazyme Biotech Co, Ltd). The bands were observed by UV irradiation. Real-time PCR analyses were performed using a SuperReal PreMix Plus Kit (SYBR Green). GAPDH was used in the circRNA and mRNA RT-qPCR analyses as an internal control, while small nuclear U6 served as the internal control in the miRNA quantitation. The relative expression levels were calculated by the $2^{-\Delta \Delta C t}$ method compared with the $\mathrm{Ct}$ values. The sequence information for the primers is listed in additional file (see section on supplementary materials given at the end of this article).

\section{RNase R treatment}

For RNase $\mathrm{R}$ digestion, the original total RNAs were divided into two equal parts, respectively, one for RNase $\mathrm{R}$ treatment (RNase $\mathrm{R}$ ) and the other for nontreatment (mock). Approximately $2 \mu \mathrm{g}$ of total RNA was incubated with or without $3 \mathrm{U} / \mu \mathrm{g}$ RNase R (Jisai Biotech, Guangzhou, China) for $30 \mathrm{~min}$ at $37^{\circ} \mathrm{C}$. Next, the digested RNA was purified according to the RNase R instructions and subsequently subjected to electrophoresis detection or RT-qPCR analysis.

\section{Vector construction and cell transfection}

The full-length sequence of circAkap17b was cloned into the original pCD2.1-ciR (7955 bp) plasmid to construct an overexpression plasmid of circAkap17b (pCD2.1circAkap17b). We selected approximately 200 sequences upstream and downstream of the circRNA binding site of miR-7b to construct the pmirGLO vector, obtaining the pmirGLO-circAkap17b-WT plasmid. The target sites of circAkap $17 \mathrm{~b}$ and miR-7b were then mutated to obtain the pmirGLO-circAkap17b-MUT plasmid. Similarly, a Luciferase reporter vector with the WT or mutant sequence of the 3' UTR of Fshb was constructed. All construct products were confirmed by sequencing (JinKairui Biotech Co. Ltd., Guangzhou, China). The detailed plasmid information is provided in the Supplementary materials. Overexpression circAkap17b plasmid was transfected into cells using Liposomal 2000 Reagent (Invitrogen by Thermo Fisher Scientific) according to the manufacturer's instruction. miR-7 miRNA mimics and inhibitors were synthesized and provided by Guangzhou RiboBio Biotech Co. Ltd, and riboFECT ${ }^{\mathrm{TM}} \mathrm{CP}$ transfection reagent was used for oligo nucleic acid transfection (e.g. siRNA, mimic, inhibitor). Cells were cultured at a density of $70-80 \%$ per well in a cell culture plate. The final concentrations of the miRNA mimics, inhibitors, and negative controls were $100 \mathrm{nM}$. The $100 \mathrm{nM}$ of miRNA mimics, inhibitors, and negative controls were used as reference concentrations.

\section{Fluorescence in situ hybridization (FISH)}

circAkap17b probes labeled with $\mathrm{Cy} 3$ and Fam-labeled miR-7 probe were designed and synthesized by RiboBio (Guangzhou, China). A Fluorescent In Situ Hybridization Kit (Ribobio Biotech) was used to determine the position of circRNA and miRNA. The hybridization operating procedures and methods were performed according to the manufacturer's instruction. A fluorescence microscope (Nikon) was used to capture images.

\section{RIP RNA immunoprecipitation assay}

RNA immunoprecipitation (RIP) experiments were performed using the Magna RIP RNA-Binding Protein Immunoprecipitation Kit (Millipore) according to the manufacturer's instructions. CST-Argonaute2 (C34C6) Rabbit mAb was purchased for RIP. Approximately $1 \times 10^{7}$ cells were collected and resuspended in RIP lysis buffer with protease and RNase inhibitor. Cell lysates were incubated with $5 \mathrm{mg}$ control mouse IgG or anti-AGO2 
antibody-coated beads, respectively, at $4^{\circ} \mathrm{C}$ overnight. After treatment with proteinase $\mathrm{K}$, immunoprecipitated RNA was extracted by phenol-chloroform extraction.

\section{FSH detection}

To avoid the effects of hormones in the serum on the accuracy of the experiment, we culture pituitary cells with serum-free medium instead of DMEM-F12 (15\%FBS) $24 \mathrm{~h}$ after transfection of plasmid or small RNA. Next, we collected serum-free medium to detect the FSH concentration after approximately $24 \mathrm{~h}$. The Rat FSH ELISA Kit (Melian Biotech Co. Ltd., Shanghai, China) was used to measure the level of FSH secreted into the culture medium.

\section{Luciferase activity assays}

We seeded 293T cells in 24-well plates with DMEM containing $10 \%$ FBS at a density of $70-80 \%$ per well for $24 \mathrm{~h}$ before transfection. Approximately $2 \mu \mathrm{L}$ of lipo2000 transfection reagent was diluted into $50 \mu \mathrm{L}$ of serum-free DMEM, and the plasmid and mimics were diluted into $50 \mu \mathrm{L}$ of serum-free DMEM medium ( $2 \mu \mathrm{g}$ of total plasmid) and then mixed and incubated at room temperature for 20 min, supplemented with $100 \mu \mathrm{L}$ of serum-free DMEM. The cells were cotransfected with a mixture in a $37^{\circ} \mathrm{C}$ incubator. After $5 \mathrm{~h}$, the original medium was discarded and 15\% FBS DMEM added to the cell culture. After $48 \mathrm{~h}$ of incubation, luciferase activity was assessed using the dual luciferase reporter assay system (Infinite M200 Pro, Tecan) according to the manufacturer's instructions. The luciferase values were normalized to the corresponding Renilla luciferase values, and then the fold changes were calculated.

\section{Statistical analysis}

All statistical analyses were performed using SPSS 19.0 software (IBM, SPSS). The unpaired $t$-test was used for two-group comparisons, and all data are expressed as the mean \pm s.e.m. of three independent experiments. Comparisons among three or multiple groups were performed by one-way ANOVA. Statistical significance was indicated by $\mathrm{p}$ values less than 0.05 . ${ }^{*} P<0.05,{ }^{* *} P<0.01$, ${ }^{* * *} P<0.001$.

\section{Results}

\section{Identification and characterization of circAkap17b in rat pituitary cells}

To verify the accuracy of the circRNA sequencing, we respectively detected the expression of rno_circ_0004036 in the pituitary of rats at 15 and 60 days by quantitative RT PCR (qRT-PCR), and we found that the expression of rno_circ_0004036 was significantly lower in mature rat anterior pituitary tissues (60D), which was consistent with the sequencing results (Supplementary material S1). Next, we affirmed the location information of rno_circ_0004036 on the chromosome via sequence analysis and blat of circ_004036. It was derived from Exon 3 to Exon 6 of the A kinase (PRKA) anchor protein 17B (Akap17b) gene (Rat genome (Rnor_6.0), ChrX:123,217,326123,254,557), herein termed circAkap17b (1204 nt) and initially identified (Fig. 1A). We subsequently designed divergent primers to amplify the back-spliced junction of circAkap17b and analyzed it by agarose gel electrophoresis and Sanger sequencing (Fig. 1B).

To confirm the circular characteristics of circAkap17b, divergent primers and convergent primers were designed to detect circAkap $17 \mathrm{~b}$ and linear $A k a p 17 \mathrm{~b}$ mRNA in reversetranscribed RNA (cDNA) and genomic DNA (gDNA). The results demonstrated that the divergent primers could amplify circAkap $17 \mathrm{~b}$ products from cDNA, while no amplification products were observed using gDNA (Fig. 1C). Furthermore, due to the circular structure of circRNA, it lacks a 3' poly(A) tail and cannot be amplified by RT using oligo dT, while random hexamers can reverse transcribe and amplify circRNA. Therefore, this experiment can be used as a method to verify the properties of circRNA. We used random hexamer or oligo $(\mathrm{dT})_{18}$ primers to carry out RT. We found that the relative expression of circAkap $17 \mathrm{~b}$ was barely detected using oligo $(\mathrm{dT})_{18}$ primers compared with random hexamer primers (Fig. 1D). To validate the stability of circAkap17b, we detected the expression of circAkap17b after RNase $\mathrm{R}$ treatment. As shown in Fig. $1 \mathrm{E}$, circAkap17b was highly resistant to RNase $\mathrm{R}$ due to it closed loop structure, while linear Akap17b mRNA was completely digested by RNase R (Fig. 1E). Fluorescence in situ hybridization (FISH) demonstrated that circAkap $17 \mathrm{~b}$ was preferentially expressed in the cytoplasm (Fig. 1F).

Taken together, these results suggest that circAkap17b is indeed a stable cytoplasmic circular molecular.

\section{circAkap17b expression pattern in rat anterior pituitary}

To determine the biological implications of circAkap17b in rat pituitary, we measured the expression of circAkap $17 \mathrm{~b}$ in six groups of rat anterior pituitary tissues: 0, 2, 3, 4, 6, and 8 weeks. The results showed that the expression level of circAkap17b was significantly reduced whereas that of circAkap17b as the same after 2 weeks (Fig. 2A). Next, we 
A
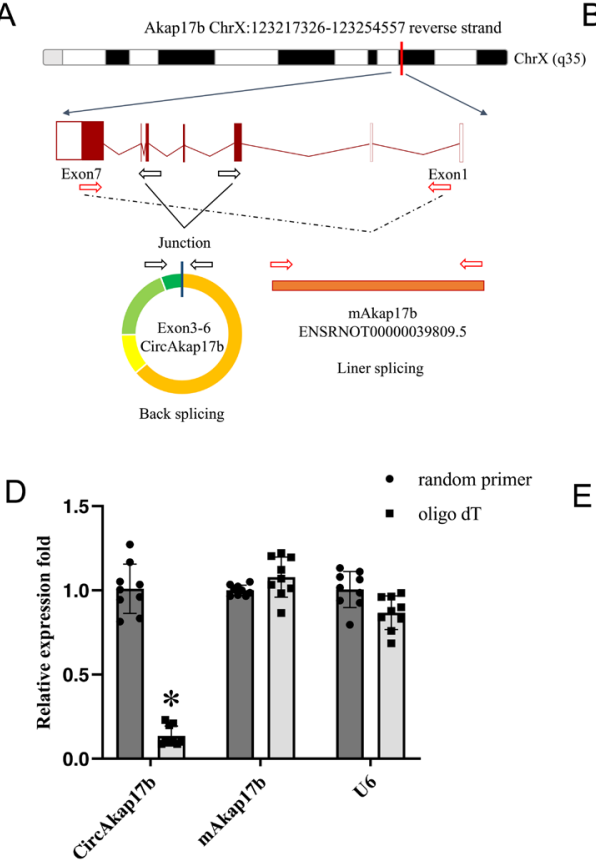

B

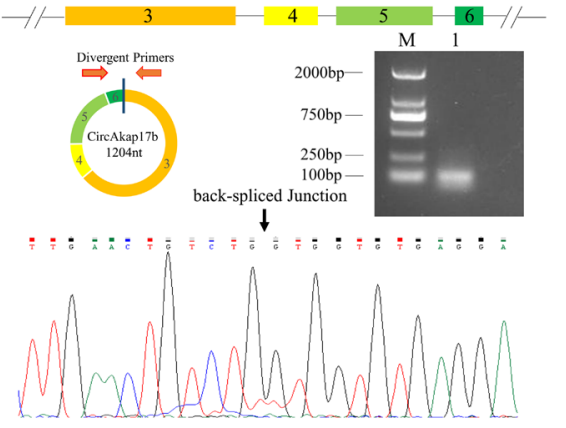

C

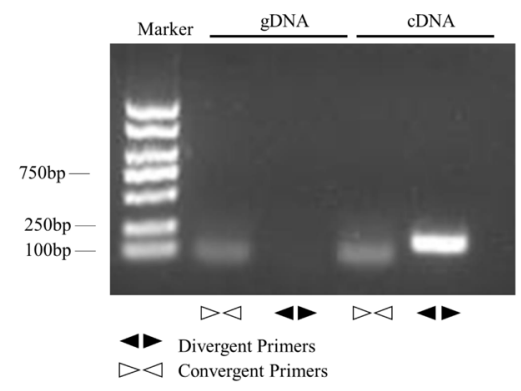

$E$

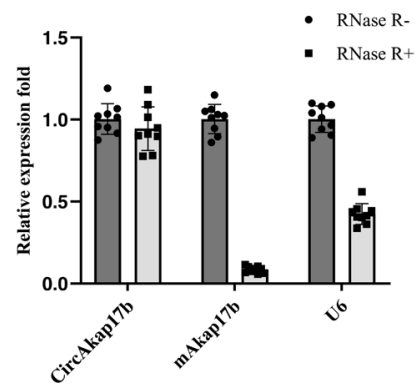

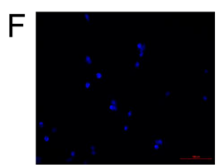
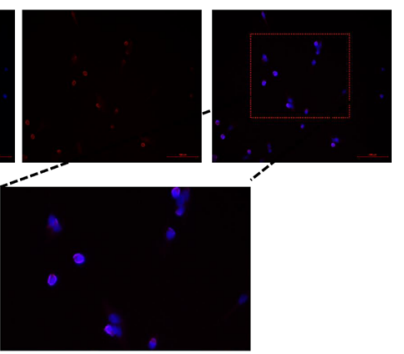

Figure 1

Identification and characterization of circAkap17b in rat pituitary cells. (A) Schematic illustration demonstrating the formation of circAkap17b. circAkap 17b is produced by the Akap17b gene of exons 3-6. (B) The presence of circAkap17b was validated by RT-PCR and agarose gel electrophoresis, followed by Sanger sequencing. The back-splice junction of circAkap17b is indicated by the black arrow. (C) RT-PCR analysis of the presence of circAkap17b in the pituitary. circAkap17b was amplified by divergent primers from CDNA but not gDNA. (D) The relative circAkap17b levels were analyzed by RT-qPCR after reverse transcription with random hexamer or oligo (dT) 18 primers. (E) RT-qPCR analysis of circAkap17b and Akap17b mRNA relative expression after treatment with RNase R. (F) RNA FISH for circAkap17b. circAkap17b probes were labeled with Cy3. Nuclei were stained with DAPI. At least three replicates of each experiment were performed. Mean values and standard deviations (SDs) of the data are shown. One-way ANOVA and the Chi-square test were applied to analyze statistical significance. $P<0.05$ was considered significant. ${ }^{*} P<0.05$. A full color version of this figure is available at https://doi.org/10.1530/JME-20-0036.

examined the circAkap17b expression level in different rat tissues. We observed lower circAkap17 expression in the heart compared with other rat tissues. In addition, the pituitary gland appeared to present the same circAkap $17 \mathrm{~b}$ expression level in the other rat tissues (Fig. 2B). We analyzed the expression pattern of circAkap $17 \mathrm{~b}$ in $\mathrm{MMQ}$, GH3 cell lines and primary cells. The results showed that
circAkap17b was significantly reduced in hypophysomal cells (Fig. 2C). Subsequently, we investigated the expression pattern of related $A k a p 17 b$ mRNAs in the pituitary. We found that $A k a p 17 b$ expression patterns were roughly consistent with circAkap17b. Akap17b mRNA expression was downregulated in mature rat pituitary (Fig. 2D) and hypophysomal cell lines (GH3, MMQ) (Fig. 2F).

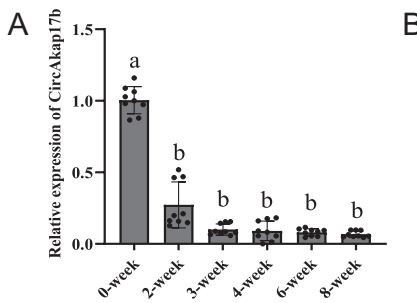

D

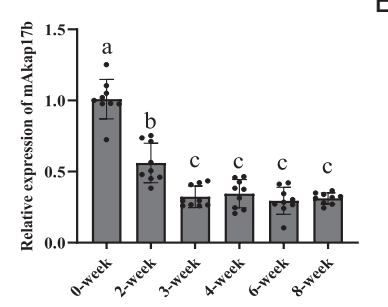

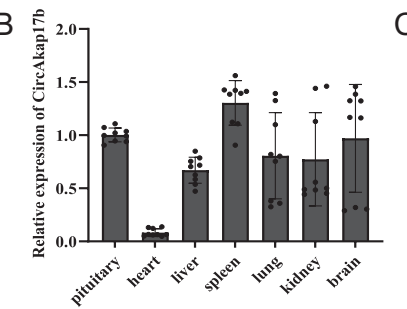

E

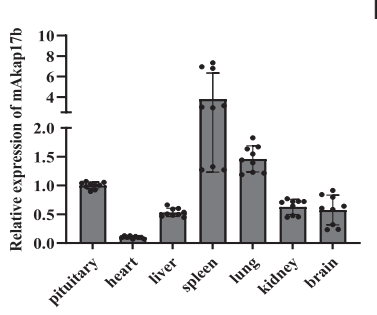

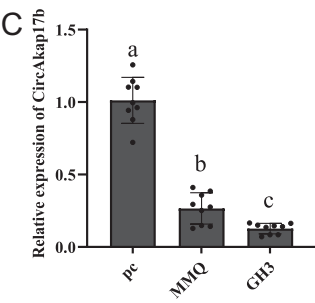

F

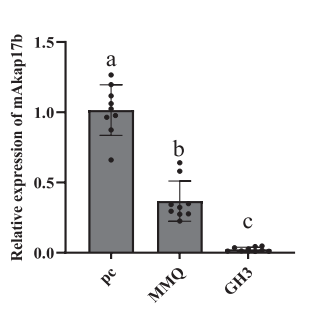

Figure 2

circAkap17b expression pattern in rat anterior pituitary. (A and D) RT-qPCR analysis of circAkap17b and Akap17b mRNA relative expression in different stages. ( $B$ and $E$ ) The relative expression level of circAkap17b and mAkap17b in mature rat different tissues. (C and F) circAkap17b and mAkap17b expression in pituitary primary cells and GH3, MMQ cell lines. At least three replicates of each experiment were performed. Mean values and S.D. of the data are shown. One-way ANOVA and the Chi-square test were applied to analyze statistical significance. $P<0.05$ was considered significant. Different letters $(a, b$ and $c)$ indicate significant differences between groups $(P<0.05)$. 
Moreover, $A k a p 17 b$ mRNA was also preferentially expressed in the pituitary and spleen (Fig. 2E).

\section{Effects of circAkap17b overexpression/blockade on Fshb transcription}

To investigate the regulatory function of circAkap $17 \mathrm{~b}$ on FSH secretion in the pituitary, we designed three short interfering RNAs (si-circAkap17b) that specifically target the back-spliced junction point of circAkap17b (Fig. 3A). A transient transfection method was used to transfect circAkap17b siRNAs into pituitary primary cells, and the siRNA knockdown efficiency was detected. We found that circAkap17b siRNA-1,2 could successfully knock down circAkap17b expression and did not influence the expression of $A k a p 17 b$ linear mRNA (Fig. 3B). Considering that siRNA-1 exhibited a higher knockdown efficiency, we selected circAkap17b siRNA-1 for the following qRT-PCR analysis, which showed that circAkap $17 \mathrm{~b}$ silencing significantly suppressed Fshb expression and FSH secretion (Fig. 3C and D). Next, we constructed an overexpression plasmid of circAkap $17 \mathrm{~b}$ based on the circularization mechanism of circRNA (Fig. 3E). In contrast, stably overexpressing circAkap17b (Fig. 3F) markedly promoted Fshb expression and FSH secretion, as shown in Fig. 3G and H. Together, these results demonstrated that circAkap17b might a potential regulatory role in FSH secretion.

\section{circAkap17b may function as a sponge for miR-7}

To explore the mechanism of ceRNA in the rat pituitary, we predicted potential target miRNAs of circAkap $17 \mathrm{~b}$ using different public databases including RegRNA2.0 (http://regrna2.mbc.nctu.edu.tw/detection.html), RNA22 (https://cm.jefferson.edu/rna22/Interactive/) and RNAhybrid (https://bibiserv.cebitec.uni-bielefeld. de/rnahybrid/). Filtering restrictions were as follows: (i) total score $\geq 150$; (ii) free energy $<-25 \mathrm{kcal} / \mathrm{mol}$; and (iii) number of estimated binding sites $\geq 1$. We identified eight candidate miRNAs that could be potential binding targets of circAkap $17 \mathrm{~b}$ and selected miR-7b based on the ranking and Targetscan database (Fig. 4A) (Supplementary material 3A). Subsequently, we found binding sites between miR-7 and circAkap $17 \mathrm{~b}$ using the RNAhybrid program (Fig. 4B). To validate whether miR-7b could interact with circAkap17b, we investigated the correlation between circAkap $17 \mathrm{~b}$ and miR-7 in pituitary cells. The results showed a negative correlation between miRNA and circRNA expression. Silencing/overexpressing circAkap $17 \mathrm{~b}$ could significantly suppress/promote miR-7 expression (Fig. 4C and D).
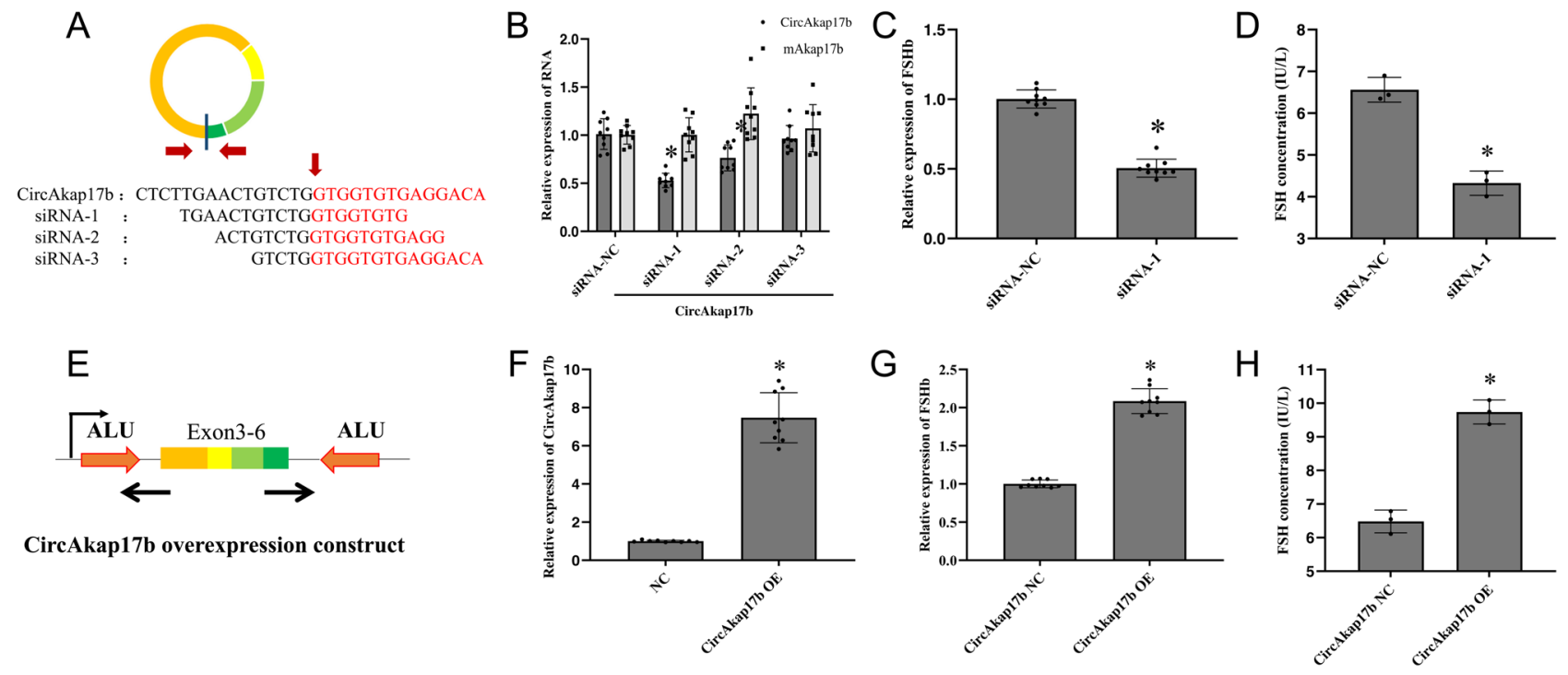

\section{Figure 3}

Effects of circAkap17b overexpression/blockade on Fshb transcription. (A) Schematic illustration showing three siRNAs at the back-splicing junction site of circAkap17b. Schematic illustration showing siRNAs and circPRKCI expression vectors. (B) The expressions of circRNA-MYLK were determined by RT-qPCR using pituitary cells were transfected with siRNAs. RT-qPCR (C) and ELISA experiment (D) revealed Fshb expression and FSH secretion after transfection with circAkap17b siRNA-1. (E) Schematic illustration showing the circAkap17b vector structure. (F and H) The Fshb expression and FSH concentration analysis after transfection of the circAkap17b overexpression vector. At least three replicates of each experiment were performed. Mean values and s.D. of the data are shown. One-way ANOVA and the Chi-square test were applied to analyze statistical significance. $P<0.05$ was considered significant. ${ }^{\star} P<0.05$. A full color version of this figure is available at https://doi.org/10.1530/JME-20-0036. 
A

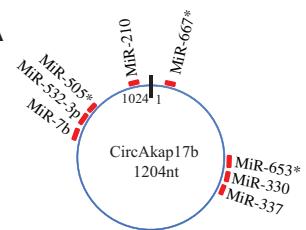

C

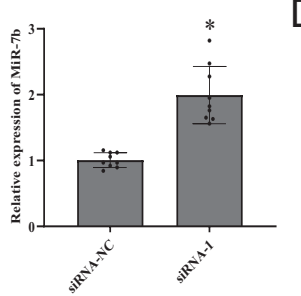

G

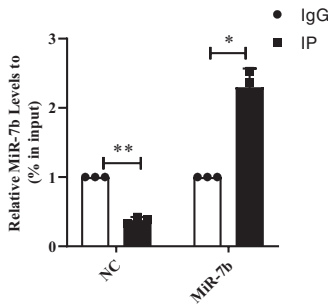

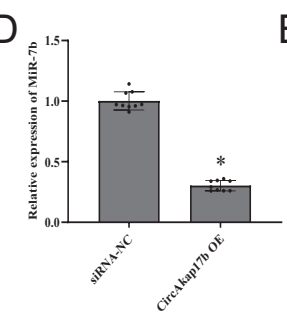

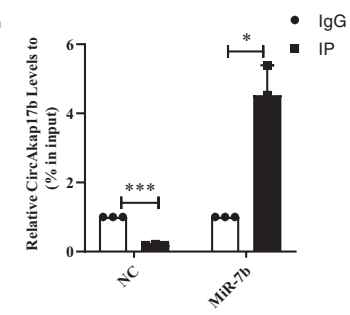

B rno-MiR-7a-5p : 3 '- UGUUGUUUUAGUGAUCAGAAGGU-5' I II II I I I CircAkap17b-WT : 5'- TCGCCAAGAGCAGGAGTCTTCCG-3'
$\begin{aligned} & \text { Position: 1027-1049 } \\ & \text { rno-MiR-7b : } 3 \text { '- UGUUGUUUUAGUGUUCAGAAGGU-5 }\end{aligned}$ rno-MiR-7b : 3 '- UGUUGUUUUAGUGUUCAGAAGGU-5' CircAkap17b-Mut : 5'- TCGCGCCAGATGAAGACTCCGGA-3'
E

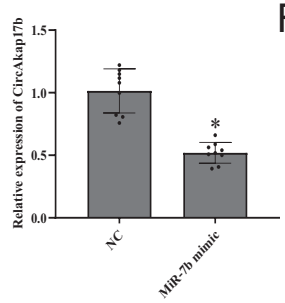

$\mathrm{F}$

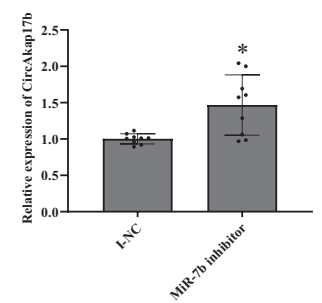

$\mathrm{H}$

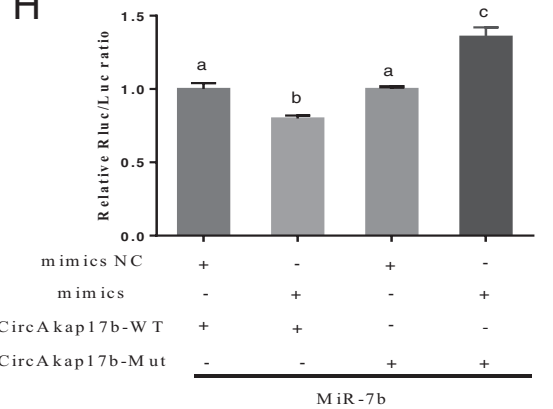

\section{Figure 4}

circAkap17b may function as a sponge for miR-7. (A) Schematic model showing the putative binding sites of 8 miRNA candidates correlated with circAkap17b (total score $\geq 150$ ). (B) Binding sites of miR-7a-5p and miR-7b in circAkap17b and mutated binding sites. (C and D) miR-7 expression increased following circAkap17b knockdown by siRNA and decreased after circAkap17b overexpression. (E and F) circAkap17b expression decreased in the presence of miR-7 mimic and increased after miR-7 inhibition. (G) The Ago2 RIP assay showed that Ago2 significantly enriched miR-7 and circAkap17b. (H) Luciferase assays were performed to detect the luciferase activities of 293T cells to confirm the interaction between miR-7 and circAkap17b. At least three replicates of each experiment were performed. Mean values and s.D. of the data are shown. One-way ANOVA and the Chi-square test were applied to analyze statistical significance. $P<0.05$ was considered significant. $* P<0.05$; $* \star P<0.01, * \star \star P<0.001$. Different letters (a, b and $\mathrm{c}$ ) indicate significant differences between groups $(P<0.05)$. A full color version of this figure is available at https://doi.org/10.1530/JME-20-0036.

Moreover, circAkap17b expression levels were significantly decreased after transfection of miR-7 mimic but increased after transfection of miR-7 inhibitor (Fig. 4E and F). To further verify the direct binding between circAkap $17 \mathrm{~b}$ and miR-7, AGO2 immunoprecipitation and the dual luciferase reporter assay were performed. As shown in Fig. $4 \mathrm{G}$, miR-7b and circAkap17b were specifically enriched in miR-7b-transfected cells. Furthermore, compared with the control negative, miR-7b transfection significantly reduced luciferase reporter activity when miR-7b mimics were cotransfected into 293T cells with luciferase reporters. We observed no difference in luciferase reporter activity between miR-7b mimics and the negative control after mutation of the predicted binding sites for miR-7b (Fig. 4H). Taken together, these results confirmed that circAkap17b could serve as the miR-7 sponge and indirectly regulate target genes. Construction of pmirGLOcircAkap17-WT and pmirGLO-circAkap17-MUT reporter plasmid and detailed information for the Ago2 RIP are provided in Supplementary material 2 and 3.

\section{miR-7b inhibits FSH secretion by targeting Fshb}

To verify whether miR-7b could target Fshb, we first predicted the interaction site between miR-7b and Fshb using the Targetscan (http://www.targetscan.org/ vert_71/) and RNAhybrid programs. Interestingly, miR-7b and miR-7a-5p were consistent with the interaction site of Fshb (Fig. 5A). Next, we cloned the 200 bp upstream and downstream of the Fshb 3' UTR and miR-7 binding sites between the XhoI (CTCGAG) and SalI (GTCGAC) sites of the pmirGLO plasmid to obtain the pmirGLO-Fshb 3'UTR-WT plasmid. We further mutated the predicted target sequence, forming the pmirGLO-Fshb $3^{\prime}$ UTR-MUT reporter plasmid. A sequencing map confirmed that the target sequences were mutated successfully (Fig. 5B). Thereafter, a double luciferase reporter assay was performed to further confirm the interaction between miR-7b and $F s h b$. We observed significantly reduced luciferase activity after cotransfection of pmirGLO-Fshb-3'UTR WT plasmid and miR-7b mimics into 293T cells compared with the 
A

rno-MiR-7a-5p : 3 '-UGUUGUUUUAGUGAUCAGAAGGU-5' FSHB 3'UTR -WT : 5'-GAAAAGAAAGGCA | | | | | 503-526 ||| |||| rno-MiR-7b

3'- UGUUGUUUUAGUGUUCAGAAGGU-5'

FSHB 3'UTR-Mut：5'-GAMAGAGGGAATGGACTCCATTGC-3'
B

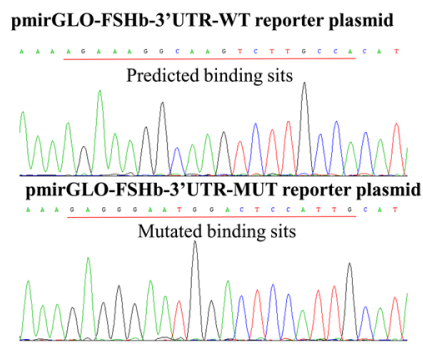

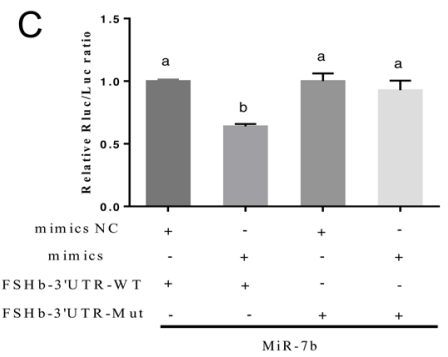
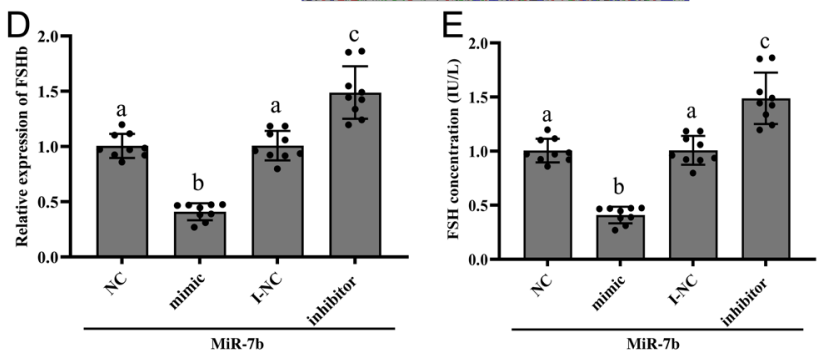

Figure 5

miR-7b inhibits FSH secretion by targeting Fshb. (A) A schematic drawing showed the predicted binding sites of miR-7 with respect to the Fshb 3' UTR. (B) A sequencing map showing the target sequence of pmirGLO- Fshb-WT and mutated target sequence from AGAAAGGCAAGTCTTGCCA to GAGGGAATGGACTCCATTG. (C) Luciferase activity assays were performed after transfection of 293T cells with different vectors. (D) The relative Fshb expression levels transfected with miR-7b were analyzed by qRT-PCR. (E) The FSH concentration of supernatant transfected with miR-7b was measured by ELISA. At least three replicates of each experiment were performed. Mean values and standard deviations (SDs) of the data are shown. One-way ANOVA and the Chi-square test were applied to analyze statistical significance. Different letters ( $a$ and $b$ ) indicate significant differences between groups $(P<0.05)$. $P<0.05$ was considered significant. A full color version of this figure is available at https://doi.org/10.1530/JME-20-0036.

miRNA control negative. No significant difference was detected after cotransfection of the pmirGLO-Fshb3'UTR mutated (MUT) plasmid and miR-7b into 293T cells (Fig. 5C). Furthermore, the expression levels of Fshb were significantly decreased after $24 \mathrm{~h}$ of transfecting miR-7b mimic into primary pituitary cells, while the relative expression of $F S H b$ increased by 1.49 -fold after transfection with a miR-7b inhibitor (Fig. 5D). Consistent with the RT-qPCR results, the ELISA showed that miR-7b mimic suppressed FSH secretion, while miR-7b inhibitor facilitated FSH secretion (Fig. 5E). To detect the effect of cells caused by miRNA transfection, we performed flow cytometry to examine cell apoptosis. The results revealed no significant difference among the four groups (NC, miRNA mimic, I-NC, and inhibitor), which indicated that the transfection experiment had no effect on cell viability (Supplementary material 4). Collectively, these results confirmed that miR-7b bound to the FSHb 3' UTR in the cytoplasm and inhibited FSH secretion.

\section{circAkap17b facilitates FSH secretion through the miR-7-Fshb pathway}

We conducted rescue experiments to confirm that circAkap17b could regulate biological progression through the circRNA-miRNA-mRNA axis. We found that knockdown of circAkap17b inhibited Fshb expression, while it alleviated inhibition efficiency caused by circAkap17b after cotransfection of circAkap17b siRNA and miR-7 inhibitor (Fig. 6A). In contrast, the relative expression level of Fshb and FSH secretion significantly increased after overexpression of circAkap17b, while cotransfection of pCD2.1-circAkap17b plasmid and miR-7 mimic counteracted its facilitating effect (Fig. 6B). In addition, the ELISA results showed that the miR-7 inhibitor alleviated the inhibitory effect caused by si-circAkap $17 \mathrm{~b}$ and facilitating effect caused by overexpression of circAkap17b (Fig. 6C and D). These results indicated that circAkap17b could promote Fshb expression and FSH secretion via the circAkap17b-miR-7-Fshb axis.

\section{Discussion}

circRNAs, generated from precursor mRNA (pre-mRNA) back-splicing of thousands of genes (Li et al. 2018), have received extensive attention worldwide due to their cyclization structural specificity and enrichment in the eukaryotic transcriptome ( $\mathrm{Qu}$ et al. 2015). circRNAs can be classified into three subclasses based on pathways by which they are generated: exonic circular RNAs (ecRNA), intronic circular RNAs (ciRNA), and exon-intron circular RNAs (EIciRNA) (Quan \& Li 2018). The present study demonstrated that a large number of circRNAs were derived from coding exons, whereas they are less 

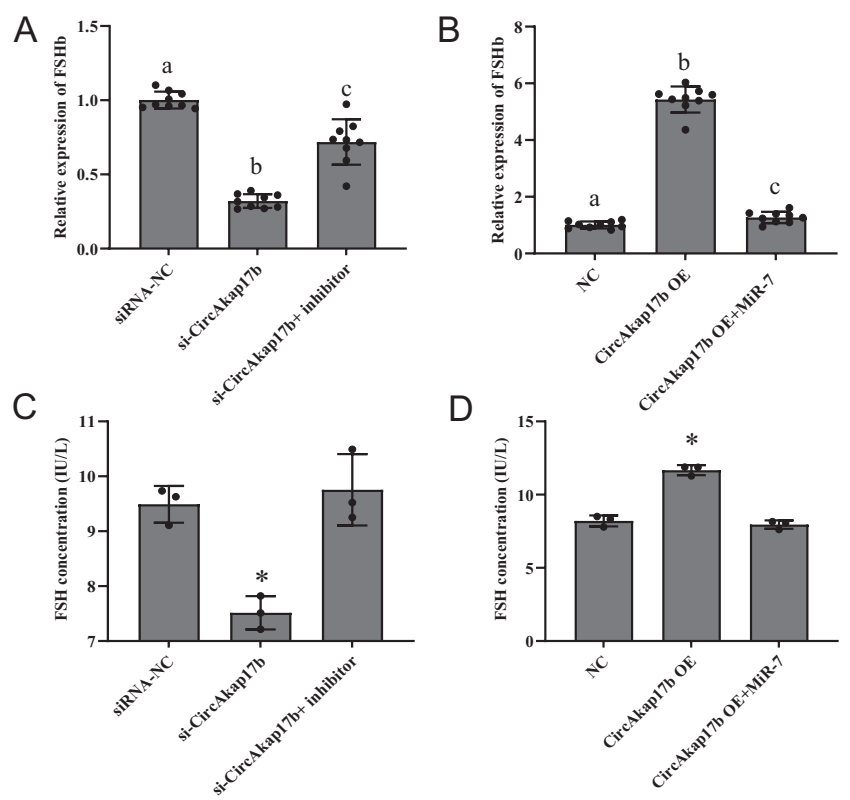

\section{Figure 6}

circAkap17b facilitates FSH secretion through the miR-7-Fshb pathway. (A) Relative Fshb expression levels transfected with si-circAkap17b or cotransfected with si-circAkap17b and miR-7 inhibitor were analyzed by qRT-PCR. (B) Relative Fshb expression levels transfected with circAkap17b OE plasmid or cotransfected with circAkap17b OE plasmid and miR-7. (C) FSH secretion levels transfected with si-circAkap17b or cotransfected with si-circAkap17b and miR-7 inhibitor were analyzed by ELISA. (D) FSH secretion levels transfected with circAkap17b OE or cotransfected with circAkap17b OE and miR-7. At least three replicates of each experiment were performed. Mean values and S.D. of the data are shown. One-way ANOVA and the Chi-square test were applied to analyze statistical significance. Different letters ( $a$ and $b$ ) indicate significant differences between groups $(P<0.05) . P<0.05$ was considered significant. $* P<0.05$.

commonly derived from intronic or intergenic regions (Memczak et al. 2013). We identified a new circRNA in the rat pituitary gland, circAkap17b, which might be involved in the regulation of animal reproduction. We affirmed location of circAkap17b in the rat chromosome using the UCSC (http://genome.ucsc.edu/) and Ensemble (http:// asia.ensembl.org/index.html) genome browser according to the circAkap17b sequence. circAkap17b is an exonic circular RNA consisting of four exons from $A k a p 17 b$ exon 3 to exon 6. A subsequent series of experiments confirmed that circAkap17b was indeed a stable cytoplasmic circular RNA molecule. In the nucleus, exons 3-6 of the Akap17b gene are circularized to form circAkap17b and miR-7 genes produce pri-miR-7 through the action of RNA polymerase II transcribing miRNAs. Pri-miR-7 are processed into 70-120nt stem-loop pre-miR-7 via Drosha endonuclease and the DGCR8 complex, and are exported to the cytoplasm through Exportin 5. In the cytoplasm, mature miR-7 are produced from pre-miRNAs through the RNase endonuclease Dicer. Mature miR-7 are incorporated into the RISC, binding to Fshb and inhibiting Fshb translation. However, cytoplasmic circAkap17b can competitively bind to miR-7 and block the inhibitory effect of miR-7 on FSH, promoting Fshb expression and FSH secretion (Fig. 7).

circRNAs are generally expressed at low levels and often exhibit complex stage- and tissue-specific expression patterns (Salzman et al. 2013, Guo et al. 2014, Szabo et al. 2015). circRNAs are more ubiquitously expressed, and they are especially abundant in the mammalian brain (Rybak-Wolf et al. 2015, Szabo et al. 2015, You et al. 2015). In this study, we found that circAkap $17 \mathrm{~b}$ expression was downregulated in the nonsexual stage. Furthermore, circAkap17b showed widespread expression in different rat tissues and was relatively enriched in spleen. These results indicated that circAkap17b might play an important regulatory role in the spleen. We focused on the expression of circAkap17b in the pituitary. Compared with primary pituitary cells, the expression level of circAkap17b was significantly reduced in pituitary tumor cells (GH3, MMQ). In summary, these results show that circAkap17b exhibits stage-specific, tissue-specific, and cell-type-specific expression patterns, suggesting a potentially regulatory role for circAkap $17 \mathrm{~b}$ in the rat pituitary.

Gonadotropin follicle-stimulating hormone (FSH), composed of a common $\alpha$ subunit and a unique $\beta$ subunit, plays a key role in regulating mammalian reproductive development (Ulloa-Aguirre et al. 1995, Lamminen et al. 2005). Many factors can regulate $F s h b$ expression and influence FSH secretion, such as gonadotropin releasing hormone (GnRH) (Miller et al. 2002), inhibin (De Jong 1988), testosterone (Noguchi et al. 1996), and miRNAs (Han et al. 2017b, 2018b, Wang et al. 2019a). However, the underlying functions and regulatory mechanisms of ncRNAs, particularly circRNAs, in FSH secretion have rarely been reported. Here we found that knockdown/ overexpression of circAkap17b could affect Fshb expression and FSH secretion. Our results demonstrated that circAkap17b might regulate the expression levels of $F s h b$ through certain underlying mechanisms.

Endogenous circRNAs exert their functions through distinct mechanisms, such as promoting transcription of their parental gene, competitive binding to miRNA response elements (MREs), interactions with RNA-binding proteins, competition for linear splicing, and protein encoding genes (Ebbesen et al. 2017, Li et al. 2018). There is a popular trend in which the circRNA functions as a miRNA or RNA-binding protein sponge to regulate various physiological activities and diseases. In cancer, an increasing number of studies have described circRNAs 


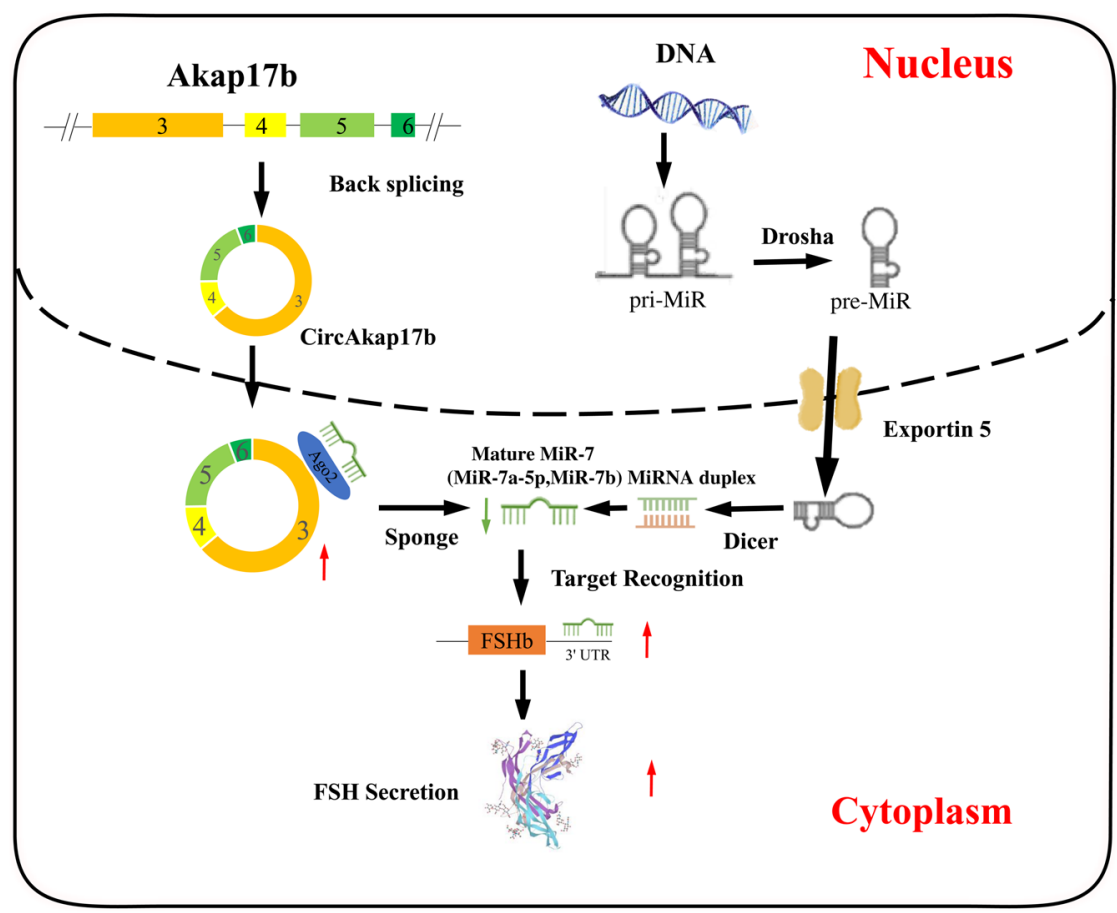

\section{Figure 7}

Schematic illustration of the circAkap17b/ miR-7/Fshb axis. Schematic diagram showing the underlying circAkap17b mechanism as a ceRNA for miR-7. A full color version of this figure is available at https://doi.org/10.1530/JME-20-0036.

functioning as ceRNAs to participate in cancer progression and malignancy (Zhao \& Shen 2017, Cui et al. 2018, Qu et al. 2018, Shang et al. 2019). circRNAs act as miRNA sponges to mediate the progression of diverse tumor types, such as non-small cell lung cancer (Chen et al. 2019b), bladder cancer (Li et al. 2017), colorectal cancer (Weng et al. 2017), human oral squamous cell carcinoma (OSCC) (Chen et al. 2017), hepatocellular carcinoma (Yu et al. 2018), gastric cancer (Zhang et al. 2019c), and osteosarcoma (Wu et al. 2019b). The occurrence of tumor cell proliferation, migration, invasion, apoptosis, and other processes are frequently associated with circRNA aberrant expression (Han et al. 2017a, Meng et al. 2017, Yang et al. 2017a, 2019, Zhong et al. 2017, Zeng et al. 2018). In addition to functioning as a ceRNA in cancer, circRNAs play an important role in the regulation of physiological processes. For example, circRNA_0046366 inhibits hepatocellular steatosis through miR-34a-PPAR signaling (Guo et al. 2018), circHIPK3 regulates cell growth by sponging multiple miRNAs (Yuan et al. 2016), circRNA (HRCR) directly targets miR-223 to protect the heart from pathological hypertrophy and heart failure (Wang et al. 2016), and circVMA21 protects against intervertebral disc degeneration through the miR-200cXIAP pathway (Cheng et al. 2018), among others (Wei et al. 2017, Han et al. 2018a, Liu et al. 2019c). However, the function and regulatory mechanism of circRNA in the pituitary is unclear. In the present study, we found that circAkap17b could act as a miR-7 sponge, as detected via Printed in Great Britain dual luciferase reporter analysis, RIP, and RT-qPCR. These results suggested that circAkap17b could competitively bind to miR-7 and might alleviate the inhibitory effect of miR-7 on target genes.

In comparison to circRNAs, miRNA (miRNAs) are a large family of short ( $22 \mathrm{nt})$ noncoding single-stranded ribonucleic acids (Yates et al. 2013). miRNAs guide the Argonaute protein Ago2 to mRNAs of encoding genes and form a ribonucleoprotein complex called the RNAinduced silencing complex (RISC) (Mohr \& Mott 2015, $\mathrm{Lu} \&$ Rothenberg 2018). In the cytoplasm, miRNAs can suppress the expression level of most mRNAs by recognizing the 3' UTR sequence of target messenger RNAs to regulate a variety of biological functions (Ambros 2004, Bartel 2009). In addition, certain miRNAs appear to have distinct tissue specificities (e.g. miR-124a, nervous systems; miR-122, liver; miR-206, muscles; miR-126, blood vessels and heart; miR-200a, lateral line system and sensory organs; miR-30c, pronephros (Wienholds et al. 2005, Landgraf et al. 2007)). miR-7 is abundant in the pituitary and brain, and it has been reported to be involved in various physiological processes (Li et al. 2016, Zhang et al. 2017b, Luo et al. 2018) as well as tumor diseases (Comi 1993, Wan et al. 2017, Wu et al. 2017, Xia et al. 2018). In our previous study, we demonstrated that miR-7a-5p can suppress the expression level of FSH by targeting Fshb (Wang et al. 2019a). Additionally, considering that miR-7b is a member of the miR-7 family, we demonstrated that miR-7b also can suppress $F s h b$ expression and FSH 
secretion by targeting Fshb. These findings have enriched research on the functional mechanism underlying the regulatory role of miRNA in hormone secretion in the pituitary.

Originally identified as star circRNA, Cdr1as/ciRS-7 is highly abundant in the mammalian brain (Hansen et al. 2013). Surprisingly, it strongly alters the free concentration of miR-7, resulting in increased levels of miR-7 targets (Memczak et al. 2013, Piwecka et al. 2017). There is emerging evidence supporting that ciRS-7 serves as a miR-7 sponge to regulate biological processes (Xu et al. 2015, Geng et al. 2016, Li et al. 2019b, Wang et al. $2019 b$ ) and cancer progression (Liu et al. 2018, Li et al. 2019a, Liu et al. 2019b, Wang et al. 2019b). circAkap17b, the function of which is consistent with Cdr1as, can act as a ceRNA to regulate gene transcription. In this study, we identified, for the first time, that circAkap $17 \mathrm{~b}$ acts as a miR-7 sponge in rat pituitary.

Taken together, our results illustrate the molecular mechanism through which circAkap17b regulates Fshb expression in rat pituitary at the posttranscriptional level and contributes to pituitary development and reproduction. These results confirm that circAkap17b can base pair with and competitively bind to miR-7 and prevent its enrichment in target mRNA, thus facilitating $F s h b$ transcription and FSH secretion in the rat pituitary. These findings contribute to reproductive development and enrich circRNA potential function.

\section{Supplementary materials}

This is linked to the online version of the paper at https://doi.org/10.1530/ JME-20-0036.

\section{Declaration of interest}

The authors declare that there is no conflict of interest that could be perceived as prejudicing the impartiality of the research reported.

\section{Funding}

This study was supported by the National Natural Science Foundation of China (31872349) and the Science and Technology Project of Jilin Province (20190201166JC).

\section{References}

Ahmed K, Lapierre MP, Gasser E, Denzler R, Yang Y, Rulicke T, Kero J, Latreille M \& Stoffel M 2017 Loss of microRNA-7a2 induces hypogonadotropic hypogonadism and infertility. Journal of Clinical Investigation 127 1061-1074. (https://doi.org/10.1172/JCI90031)
Amar L, Benoit C, Beaumont G, Vacher CM, Crepin D, Taouis M \& Baroin-Tourancheau A 2012 MicroRNA expression profiling of hypothalamic arcuate and paraventricular nuclei from single rats using Illumina sequencing technology. Journal of Neuroscience Methods 209 134-143. (https://doi.org/10.1016/j.jneumeth.2012.05.033)

Ambros V 2004 The functions of animal microRNAs. Nature 431 350-355. (https://doi.org/10.1038/nature02871)

Bartel DP 2009 MicroRNAs: target recognition and regulatory functions. Cell 136 215-233. (https://doi.org/10.1016/j.cell.2009.01.002)

Chen LL 2016 The biogenesis and emerging roles of circular RNAs. Nature Reviews: Molecular Cell Biology 17 205-211. (https://doi. org/10.1038/nrm.2015.32)

Chen LL \& Yang L 2015 Regulation of circRNA biogenesis. RNA Biology 12 381-388. (https://doi.org/10.1080/15476286.2015.1020271)

Chen L, Zhang S, Wu J, Cui J, Zhong L, Zeng L \& Ge S 2017 circRNA_100290 plays a role in oral cancer by functioning as a sponge of the miR-29 family. Oncogene 36 4551-4561. (https://doi. org/10.1038/onc.2017.89)

Chen B, Wei W, Huang X, Xie X, Kong Y, Dai D, Yang L, Wang J, Tang H \& Xie X 2018 circEPSTI1 as a prognostic marker and mediator of triple-negative breast cancer progression. Theranostics 8 4003-4015. (https://doi.org/10.7150/thno.24106)

Chen B, Li Y, Liu Y \& Xu Z 2019a circLRP6 regulates high glucoseinduced proliferation, oxidative stress, ECM accumulation, and inflammation in mesangial cells. Journal of Cellular Physiology 234 21249-21259. (https://doi.org/10.1002/jcp.28730)

Chen L, Nan A, Zhang N, Jia Y, Li X, Ling Y, Dai J, Zhang S, Yang Q, Yi Y, et al. 2019b Circular RNA 100146 functions as an oncogene through direct binding to miR-361-3p and miR-615-5p in non-small cell lung cancer. Molecular Cancer 18 13. (https://doi.org/10.1186/ s12943-019-0943-0)

Cheng X, Zhang L, Zhang K, Zhang G, Hu Y, Sun X, Zhao C, Li H, Li YM \& Zhao J 2018 Circular RNA VMA21 protects against intervertebral disc degeneration through targeting miR-200c and $\mathrm{X}$ linked inhibitor-of-apoptosis protein. Annals of the Rheumatic Diseases 77 770-779. (https://doi.org/10.1136/ annrheumdis-2017-212056)

Cocquerelle C, Mascrez B, Hetuin D \& Bailleul B 1993 Mis-splicing yields circular RNA molecules. FASEB Journal 7 155-160. (https://doi. org/10.1096/fasebj.7.1.7678559)

Comi RJ 1993 Approach to acute hypoglycemia. Endocrinology and Metabolism Clinics of North America 22 247-262. (https://doi. org/10.1016/S0889-8529(18)30164-6)

Cui X, Wang J, Guo Z, Li M, Li M, Liu S, Liu H, Li W, Yin X, Tao J, et al. 2018 Emerging function and potential diagnostic value of circular RNAs in cancer. Molecular Cancer 17 123. (https://doi.org/10.1186/ s12943-018-0877-y)

De Jong FH 1988 Inhibin. Physiological Reviews 68 555-607. (https://doi. org/10.1152/physrev.1988.68.2.555)

Dong Y, He D, Peng Z, Peng W, Shi W, Wang J, Li B, Zhang C \& Duan C 2017 Circular RNAs in cancer: an emerging key player. Journal of Hematology and Oncology 10 2. (https://doi.org/10.1186/s13045-0160370-2)

Dube U, Del-Aguila JL, Li Z, Budde JP, Jiang S, Hsu S, Ibanez L, Fernandez MV, Farias F, Norton J, et al. 2019 An atlas of cortical circular RNA expression in Alzheimer disease brains demonstrates clinical and pathological associations. Nature Neuroscience 22 1903-1912. (https://doi.org/10.1038/s41593-019-0501-5)

Ebbesen KK, Hansen TB \& Kjems J 2017 Insights into circular RNA biology. RNA Biology 14 1035-1045. (https://doi.org/10.1080/154762 86.2016.1271524)

Fauquier T, Lacampagne A, Travo P, Bauer K \& Mollard P 2002 Hidden face of the anterior pituitary. Trends in Endocrinology and Metabolism 13 304-309. (https://doi.org/10.1016/s1043-2760(02)00616-1)

Fernandez-De Frutos M, Galan-Chilet I, Goedeke L, Kim B, PardoMarques V, Perez-Garcia A, Herrero JI, Fernandez-Hernando C, Kim J https://jme.bioscientifica.com

https://doi.org/10.1530/JME-20-0036 (c) 2020 Society for Endocrinology Published by Bioscientifica Ltd. Printed in Great Britain 
\& Ramirez CM 2019 MicroRNA 7 impairs insulin signaling and regulates Abeta levels through posttranscriptional regulation of the insulin receptor substrate 2 , insulin receptor, insulin-degrading enzyme, and liver X receptor pathway. Molecular and Cellular Biology 39 e00170-19. (https://doi.org/10.1128/МСВ.00170-19)

Gao Y, Li J, Zhang Z, Zhang R, Pollock A \& Sun T 2019 MicroRNA miR-7 and miR-17-92 in the arcuate nucleus of mouse hypothalamus regulate sex-specific diet-induced obesity. Molecular Neurobiology 56 7508-7521. (https://doi.org/10.1007/s12035-019-1618-y)

Garikipati VNS, Verma SK, Cheng Z, Liang D, Truongcao MM, Cimini M, Yue Y, Huang G, Wang C, Benedict C, et al. 2019 Circular RNA circFndc3b modulates cardiac repair after myocardial infarction via FUS/VEGF-A axis. Nature Communications 10 4317. (https://doi. org/10.1038/s41467-019-11777-7)

Geng HH, Li R, Su YM, Xiao J, Pan M, Cai XX \& Ji XP 2016 The circular RNA Cdr1as promotes myocardial infarction by mediating the regulation of miR-7a on its target genes expression. PLOS ONE 11 e0151753. (https://doi.org/10.1371/journal.pone.0151753)

Guo JU, Agarwal V, Guo H \& Bartel DP 2014 Expanded identification and characterization of mammalian circular RNAs. Genome Biology 15 409. (https://doi.org/10.1186/s13059-014-0409-z)

Guo Y, Luo F, Liu Q \& Xu D 2017 Regulatory non-coding RNAs in acute myocardial infarction. Journal of Cellular and Molecular Medicine 21 1013-1023. (https://doi.org/10.1111/jcmm.13032)

Guo XY, Sun F, Chen JN, Wang YQ, Pan Q \& Fan JG 2018 circRNA_0046366 inhibits hepatocellular steatosis by normalization of PPAR signaling. World Journal of Gastroenterology 24 323-337. (https://doi.org/10.3748/wjg.v24.i3.323)

Guo G, Wang H, Ye L, Shi X, Yan K, Lin K, Huang Q, Li B, Lin Q, Zhu L, et al. 2019a Hsa_circ_0000479 as a novel diagnostic biomarker of systemic lupus erythematosus. Frontiers in Immunology 10 2281. (https://doi.org/10.3389/fimmu.2019.02281)

Guo T, Zhang J, Yao W, DU, Li X, Huang Q, Ma L, Li M, Liu Q, H, et al. $2019 b$ circINHA resists granulosa cell apoptosis by up-regulating CTGF as a ceRNA of miR-10a-5p in pig ovarian follicles. Biochimica et Biophysica Acta: Gene Regulatory Mechanisms 1862 194420. (https:// doi.org/10.1016/j.bbagrm.2019.194420)

Han D, Li J, Wang H, Su X, Hou J, Gu Y, Qian C, Lin Y, Liu X, huang M, et al. 2017a Circular RNA circMTO1 acts as the sponge of microRNA-9 to suppress hepatocellular carcinoma progression. Hepatology 66 1151-1164. (https://doi.org/10.1002/hep.29270)

Han DX, Sun XL, Xu MQ, Chen CZ, Jiang H, Gao Y, Yuan B \& Zhang JB $2017 b$ Roles of differential expression of microRNA-21-3p and microRNA-433 in FSH regulation in rat anterior pituitary cells. Oncotarget 8 36553-36565. (https://doi.org/10.18632/oncotarget.16615)

Han B, Zhang Y, Zhang Y, Bai Y, Chen X, Huang R, Wu F, Leng S, Chao J, Zhang JH, et al. 2018a Novel insight into circular RNA HECTD1 in astrocyte activation via autophagy by targeting MIR142TIPARP: implications for cerebral ischemic stroke. Autophagy $\mathbf{1 4}$ 1164-1184. (https://doi.org/10.1080/15548627.2018.1458173)

Han DX, Xiao Y, Wang CJ, Jiang H, Gao Y, Yuan B \& Zhang JB 2018b Regulation of FSH expression by differentially expressed miR-186-5p in rat anterior adenohypophyseal cells. PLOS ONE 13 e0194300. (https://doi.org/10.1371/journal.pone.0194300)

Han DX, Wang CJ, Sun XL, Liu JB, Jiang H, Gao Y, Chen CZ, Yuan B \& Zhang JB 2019 Identification of circular RNAs in the immature and mature rat anterior pituitary. Journal of Endocrinology 240 393-402. (https://doi.org/10.1530/JOE-18-0540)

Hansen TB, Jensen TI, Clausen BH, Bramsen JB, Finsen B, Damgaard CK \& Kjems J 2013 Natural RNA circles function as efficient microRNA sponges. Nature 495 384-388. (https://doi. org/10.1038/nature11993)

He J, Zhang J, Wang Y, Liu W, Gou K, Liu Z \& Cui S 2018 miR-7 mediates the zearalenone signaling pathway regulating FSH synthesis and secretion by targeting FOS in female pigs. Endocrinology 159 2993-3006. (https://doi.org/10.1210/en.2018-00097)
Hentze MW \& Preiss T 2013 Circular RNAs: splicing's enigma variations. EMBO Journal 32 923-925. (https://doi.org/10.1038/ emboj.2013.53)

Hong GK, Payne SC \& Jane JA JR 2016 Anatomy, physiology, and laboratory evaluation of the pituitary gland. Otolaryngologic Clinics of North America 49 21-32. (https://doi.org/10.1016/j.otc.2015.09.002)

Howles CM 2000 Role of LH and FSH in ovarian function. Molecular and Cellular Endocrinology 161 25-30. (https://doi.org/10.1016/s03037207(99)00219-1)

Hu G, Niu F, Liao K, Periyasamy P, Sil S, Liu J, Dravid SM \& Buch S 2019 HIV-1 Tat-induced astrocytic extracellular vesicle mir-7 impairs synaptic architecture. Journal of Neuroimmune Pharmacology $\mathbf{1 5}$ 538-553. (https://doi.org/10.1007/s11481-019-09869-8)

Huang S, Li X, Zheng H, Si X, Li B, Wei G, Li C, Chen Y, Chen Y, Liao W, et al. 2019a Loss of super-enhancer-regulated circRNA Nfix induces cardiac regeneration after myocardial infarction in adult mice. Circulation 139 2857-2876. (https://doi.org/10.1161/ CIRCULATIONAHA.118.038361)

Huang W, Fang K, Chen TQ, Zeng ZC, Sun YM, Han C, Sun LY, Chen $\mathrm{ZH}$, Yang QQ, Pan Q, et al. 2019b circRNA circAF4 functions as an oncogene to regulate MLL-AF4 fusion protein expression and inhibit MLL leukemia progression. Journal of Hematology and Oncology 12 103. (https://doi.org/10.1186/s13045-019-0800-z)

Jeck WR, Sorrentino JA, Wang K, Slevin MK, Burd CE, Liu J, Marzluff WF \& Sharpless NE 2013 Circular RNAs are abundant, conserved, and associated with ALU repeats. RNA 19 141-157. (https://doi. org/10.1261/rna.035667.112)

Lamminen T, Jokinen P, Jiang M, Pakarinen P, Simonsen H \& Huhtaniemi I 2005 Human FSH beta subunit gene is highly conserved. Molecular Human Reproduction 11 601-605. (https://doi. org/10.1093/molehr/gah198)

Landgraf P, Rusu M, Sheridan R, Sewer A, Iovino N, Aravin A, Pfeffer S, Rice A, Kamphorst AO, Landthaler M, et al. 2007 A mammalian microRNA expression atlas based on small RNA library sequencing. Cell 129 1401-1414. (https://doi.org/10.1016/j.cell.2007.04.040)

Legnini I, Di timoteo G, Rossi F, Morlando M, Briganti F, Sthandier O, Fatica A, Santini T, Andronache A, Wade M, et al. 2017 circ-ZNF609 is a circular RNA that can be translated and functions in myogenesis. Molecular Cell 66 22-37.e9. (https://doi.org/10.1016/j. molcel.2017.02.017)

Li YZ, Wen L, Wei X, Wang QR, Xu LW, Zhang HM \& Liu WC 2016 Inhibition of miR-7 promotes angiogenesis in human umbilical vein endothelial cells by upregulating VEGF via KLF4. Oncology Reports 36 1569-1575. (https://doi.org/10.3892/or.2016.4912)

Li Y, Zheng F, Xiao X, Xie F, Tao D, Huang C, Liu D, Wang M, Wang L, Zeng F, et al. 2017 circHIPK3 sponges miR-558 to suppress heparanase expression in bladder cancer cells. EMBO Reports 18 1646-1659. (https://doi.org/10.15252/embr.201643581)

Li X, Yang L \& Chen LL 2018 The Biogenesis, functions, and challenges of circular RNAs. Molecular Cell 71 428-442. (https://doi. org/10.1016/j.molcel.2018.06.034)

Li C, Li M \& Xue Y 2019a Downregulation of circRNA CDR1as specifically triggered low-dose Diosbulbin-B induced gastric cancer cell death by regulating miR-7-5p/REGgamma axis. Biomedicine and Pharmacotherapy 120 109462. (https://doi.org/10.1016/j. biopha.2019.109462)

Li L, Chen Y, Nie L, Ding X, Zhang X, Zhao W, Xu X, Kyei B, Dai D, Zhan S, et al. 2019b MyoD-induced circular RNA CDR1as promotes myogenic differentiation of skeletal muscle satellite cells. Biochimica et Biophysica Acta: Gene Regulatory Mechanisms 1862 807-821. (https://doi.org/10.1016/j.bbagrm.2019.07.001)

Li X, Li C, Liu Z, Ni W, Yao R, Xu Y, Quan R, Zhang M, Li H, Liu L, et al. 2019c Circular RNA circ-FoxO3 inhibits myoblast cells differentiation. Cells 8 616. (https://doi.org/10.3390/cells8060616)

Liu P, Ji Y, Yuen T, Rendina-Ruedy E, Demambro VE, Dhawan S, AbuAmer W, Izadmehr S, Zhou B, Shin AC, et al. 2017 Blocking FSH 
induces thermogenic adipose tissue and reduces body fat. Nature $\mathbf{5 4 6}$ 107-112. (https://doi.org/10.1038/nature22342)

Liu C, Yuan B, Chen H, Xu M, Sun X, Xu J, Gao Y, Chen C, Jiang H \& Zhang J 2018 Effects of miR-375-BMPR2 as a key factor downstream of BMP15/GDF9 on the Smad1/5/8 and Smad2/3 signaling pathways. Cellular Physiology and Biochemistry 46 213-225. (https://doi. org/10.1159/000488424)

Liu CX, Li X, nan F, Jiang S, Gao X, Guo SK, Xue W, Cui Y, Dong K, Ding H, et al. 2019a Structure and degradation of circular RNAs regulate PKR activation in innate immunity. Cell 177 865.e21-880. e21. (https://doi.org/10.1016/j.cell.2019.03.046)

Liu L, Yang X, Li NF, Lin L \& Luo H $2019 b$ circ_0015756 promotes proliferation, invasion and migration by microRNA-7-dependent inhibition of FAK in hepatocellular carcinoma. Cell Cycle $\mathbf{1 8}$ 2939-2953. (https://doi.org/10.1080/15384101.2019.1664223)

Liu R, Wang Q, Chang W, Zhou L, Li J \& Zhang K 2019c Characterisation of the circular RNA landscape in mesenchymal stem cells from psoriatic skin lesions. European Journal of Dermatology 29 29-38. (https://doi.org/10.1684/ejd.2018.3483)

Liu Y, Hou J, Zhang M, Seleh-Zo E, Wang J, Cao B \& An X 2019d circ016910 sponges miR-574-5p to regulate cell physiology and milk synthesis via MAPK and PI3K/AKT-mTOR pathways in GMECs. Journal of Cellular Physiology 235 4198-4216. (https://doi. org/10.1002/jcp.29370)

Lu TX \& Rothenberg ME 2018 MicroRNA. Journal of Allergy and Clinical Immunology 141 1202-1207. (https://doi.org/10.1016/j.jaci.2017.08.034)

Luo H, Liang H, Chen Y, Chen S, Xu Y, Xu L, Liu J, Zhou K, Peng J, Guo G, et al. 2018 miR-7-5p overexpression suppresses cell proliferation and promotes apoptosis through inhibiting the ability of DNA damage repair of PARP-1 and BRCA1 in TK6 cells exposed to hydroquinone. Chemico-Biological Interactions 283 84-90. (https:// doi.org/10.1016/j.cbi.2018.01.019)

McGee EA \& Hsueh AJ 2000 Initial and cyclic recruitment of ovarian follicles. Endocrine Reviews 21 200-214. (https://doi.org/10.1210/ edrv.21.2.0394)

Memczak S, Jens M, Elefsinioti A, Torti F, Krueger J, Rybak A, Maier L, Mackowiak SD, Gregersen LH, Munschauer M, et al. 2013 Circular RNAs are a large class of animal RNAs with regulatory potency. Nature 495 333-338. (https://doi.org/10.1038/nature11928)

Meng S, Zhou H, Feng Z, Xu Z, Tang Y, Li P \& Wu M 2017 circRNA: functions and properties of a novel potential biomarker for cancer. Molecular Cancer 16 94. (https://doi.org/10.1186/s12943-017-0663-2)

Miller WL, Shafiee-Kermani F, Strahl BD \& Huang HJ 2002 The nature of FSH induction by GnRH. Trends in Endocrinology and Metabolism 13 257-263. (https://doi.org/10.1016/s1043-2760(02)00614-8)

Mohr AM \& Mott JL 2015 Overview of microRNA biology. Seminars in Liver Disease 35 3-11. (https://doi.org/10.1055/s-0034-1397344)

Noguchi K, Arita J, Nagamoto A, Hosaka M \& Kimura F 1996 A quantitative analysis of testosterone action on FSH secretion from individual pituitary cells using the cell immunoblot assay. Journal of Endocrinology 148 427-433. (https://doi.org/10.1677/joe.0.1480427)

Piwecka M, Glazar P, Hernandez-Miranda LR, Memczak S, Wolf SA, Rybak-Wolf A, Filipchyk A, Klironomos F, Cerda Jara CA, Fenske P, et al. 2017 Loss of a mammalian circular RNA locus causes miRNA deregulation and affects brain function. Science $\mathbf{3 5 7}$ eaam8526. (https://doi.org/10.1126/science.aam8526)

Qu S, Yang X, Li X, Wang J, Gao Y, Shang R, Sun W, Dou K \& Li H 2015 Circular RNA: a new star of noncoding RNAs. Cancer Letters 365 141-148. (https://doi.org/10.1016/j.canlet.2015.06.003)

Qu S, Liu Z, yang X, Zhou J, Yu H, Zhang R \& Li H 2018 The emerging functions and roles of circular RNAs in cancer. Cancer Letters $\mathbf{4 1 4}$ 301-309. (https://doi.org/10.1016/j.canlet.2017.11.022)

Quan G \& Li J 2018 Circular RNAs: biogenesis, expression and their potential roles in reproduction. Journal of Ovarian Research 119. (https://doi.org/10.1186/s13048-018-0381-4)
Rybak-Wolf A, Stottmeister C, Glazar P, Jens M, Pino N, Giusti S, Hanan M, Behm M, Bartok O, Ashwal-Fluss R, et al. 2015 Circular RNAs in the mammalian brain are highly abundant, conserved, and dynamically expressed. Molecular Cell 58 870-885. (https://doi. org/10.1016/j.molcel.2015.03.027)

Salzman J, Chen RE, Olsen MN, Wang PL \& Brown PO 2013 Cell-type specific features of circular RNA expression. PLoS Genetics 9 e1003777. (https://doi.org/10.1371/journal.pgen.1003777)

Shang Q, Yang Z, Jia R \& Ge S 2019 The novel roles of circRNAs in human cancer. Molecular Cancer 18 6. (https://doi.org/10.1186/ s12943-018-0934-6)

Sheng X, Bao Y, Zhang JS, Li M, Li YN, Xu QN, Zhang SH \& Li CT 2018 Research progress on InDel genetic marker in forensic science. $\mathrm{Fa} \mathrm{Yi}$ Xue Za Zhi 34 420-427. (https://doi.org/10.12116/j.issn.10045619.2018.04.016)

Shih JC, Lin HH, Hsiao AC, Su YT, Tsai S, Chien CL \& Kung HN 2019 Unveiling the role of microRNA-7 in linking TGF-beta-Smadmediated epithelial-mesenchymal transition with negative regulation of trophoblast invasion. FASEB Journal 33 6281-6295. (https://doi. org/10.1096/fj.201801898RR)

Simoni M, Weinbauer GF, Gromoll J \& Nieschlag E 1999 Role of FSH in male gonadal function. Annales d'Endocrinologie 60 102-106.

Su H, Tao T, Yang Z, Kang X, Zhang X, Kang D, Wu S \& Li C 2019 Circular RNA cTFRC acts as the sponge of MicroRNA-107 to promote bladder carcinoma progression. Molecular Cancer 18 27. (https://doi. org/10.1186/s12943-019-0951-0)

Sun L, Peng Y, Sharrow AC, Iqbal J, Zhang Z, Papachristou DJ, Zaidi S, Zhu LL, Yaroslavskiy BB, zhou H, et al. 2006 FSH directly regulates bone mass. Cell 125 247-260. (https://doi.org/10.1016/j. cell.2006.01.051)

Szabo L, Morey R, Palpant NJ, Wang PL, Afari N, Jiang C, Parast MM, Murry CE, Laurent LC \& Salzman J 2015 Statistically based splicing detection reveals neural enrichment and tissue-specific induction of circular RNA during human fetal development. Genome Biology 16 126. (https://doi.org/10.1186/s13059-015-0690-5)

Tian S, Liu X, Fan Q, Ma J, Yao L \& Li Y 2019 Microarray expression and functional analysis of circular RNAs in the glomeruli of NZB/W F1 mice with lupus nephritis. Experimental and Therapeutic Medicine 18 2813-2824. (https://doi.org/10.3892/etm.2019.7901)

Ulloa-Aguirre A, Midgley AR, Beitins IZ \& Padmanabhan V 1995 Folliclestimulating isohormones: characterization and physiological relevance. Endocrine Reviews 16 765-787. (https://doi.org/10.1210/ edrv-16-6-765)

Wan S, Wang J, Wang J, Wu J, Song J, Zhang CY, Zhang C, Wang C \& Wang JJ 2017 Increased serum miR-7 is a promising biomarker for type 2 diabetes mellitus and its microvascular complications. Diabetes Research and Clinical Practice 130 171-179. (https://doi. org/10.1016/j.diabres.2017.06.005)

Wang K, Long B, Liu F, Wang JX, Liu CY, Zhao B, Zhou LY, Sun T, Wang M, Yu T, et al. 2016 A circular RNA protects the heart from pathological hypertrophy and heart failure by targeting miR-223. European Heart Journal 37 2602-2611. (https://doi.org/10.1093/eurheartj/ehv713)

Wang CJ, Guo HX, Han DX, Yu ZW, Zheng Y, Jiang H, Gao Y, Yuan B \& Zhang JB 2019a Pituitary tissue-specific miR-7a-5p regulates FSH expression in rat anterior adenohypophyseal cells. PeerJ 7 e6458. (https://doi.org/10.7717/peerj.6458)

Wang F, Chen X, Han Y, Xi S \& Wu G 2019b circRNA CDR1 as regulated the proliferation of human periodontal ligament stem cells under a lipopolysaccharide-induced inflammatory condition. Mediators of Inflammation 2019 1625381. (https://doi.org/10.1155/2019/1625381)

Wei X, Li H, Yang J, Hao D, Dong D, Huang Y, Lan X, Plath M, Lei C, Lin F, et al. 2017 Circular RNA profiling reveals an abundant circLMO7 that regulates myoblasts differentiation and survival by sponging miR-378a-3p. Cell Death and Disease 8 e3153. (https://doi. org/10.1038/cddis.2017.541) 
Weng W, Wei Q, Toden S, Yoshida K, Nagasaka T, Fujiwara T, Cai S, Qin H, MA, Ma Y \& Goel A 2017 Circular RNA ciRS-7-A promising prognostic biomarker and a potential therapeutic target in colorectal cancer. Clinical Cancer Research 23 3918-3928. (https://doi. org/10.1158/1078-0432.CCR-16-2541)

Wienholds E, Kloosterman WP, Miska E, Alvarez-Saavedra E, Berezikov E, De Bruijn E, Horvitz HR, Kauppinen S \& Plasterk RH 2005 MicroRNA expression in zebrafish embryonic development. Science $\mathbf{3 0 9}$ 310-311. (https://doi.org/10.1126/science.1114519)

Wu W, Liu S, Liang Y, Zhou Z \& Liu X 2017 miR-7 inhibits progression of hepatocarcinoma by targeting KLF-4 and promises a novel diagnostic biomarker. Cancer Cell International 17 31. (https://doi. org/10.1186/s12935-017-0386-x)

Wu L, Xia J, Yang J, Shi Y, Xia H, Xiang X \& Yu X 2018 circ-ZNF609 promotes migration of colorectal cancer by inhibiting Gli1 expression via microRNA-150. Journal of BUON 23 1343-1349.

Wu F, Han B, Wu S, Yang L, Leng S, Li M, Liao J, Wang G, Ye Q, Zhang Y, et al. 2019a Circular RNA TLK1 aggravates neuronal injury and neurological deficits after ischemic stroke via miR-335-3p/ TIPARP. Journal of Neuroscience 39 7369-7393. (https://doi. org/10.1523/JNEUROSCI.0299-19.2019)

Wu Y, Xie Z, Chen J, Chen J, Ni W, Ma Y, Huang K, Wang G, Wang J, Ma J, et al. 2019b Circular RNA circTADA2A promotes osteosarcoma progression and metastasis by sponging miR-203a-3p and regulating CREB3 expression. Molecular Cancer 18 73. (https://doi.org/10.1186/ s12943-019-1007-1)

Xia J, Cao T, Ma C, Shi Y, Sun Y, Wang ZP \& Ma J 2018 miR-7 suppresses tumor progression by directly targeting MAP3K9 in pancreatic cancer. Molecular Therapy: Nucleic Acids 13 121-132. (https://doi.org/10.1016/j.omtn.2018.08.012)

Xu H, Guo S, li W \& Yu P 2015 The circular RNA Cdr1as, via miR-7 and its targets, regulates insulin transcription and secretion in islet cells. Scientific Reports 5 12453. (https://doi.org/10.1038/srep12453)

Xue D, Wang H, Chen Y, Shen D, Lu J, Wang M, Zebibula A, Xu L, Wu H, Li G, et al. 2019 circ-AKT3 inhibits clear cell renal cell carcinoma metastasis via altering miR-296-3p/E-cadherin signals. Molecular Cancer 18 151. (https://doi.org/10.1186/s12943-019-1072-5)

Yang Q, Du WW, Wu N, Yang W, Awan FM, Fang L, Ma J, Li X, Zeng Y, Yang Z, et al. 2017a A circular RNA promotes tumorigenesis by inducing c-myc nuclear translocation. Cell Death and Differentiation 24 1609-1620. (https://doi.org/10.1038/cdd.2017.86)

Yang Y, Fan X, Mao M, Song X, Wu P, Zhang Y, Jin Y, Yang Y, Chen LL, Wang Y, et al. 2017b Extensive translation of circular RNAs driven by N(6)-methyladenosine. Cell Research 27 626-641. (https://doi. org/10.1038/cr.2017.31)

Yang ZG, Awan FM, Du WW, Zeng Y, Lyu J, Wu, Gupta S, Yang W \& Yang BB 2017c The circular RNA interacts with STAT3, increasing its nuclear translocation and wound repair by modulating Dnmt3a and miR-17 function. Molecular Therapy 25 2062-2074. (https://doi. org/10.1016/j.ymthe.2017.05.022)

Yang R, Xing L, Zheng X, Sun Y, Wang X \& Chen J 2019 The circRNA circAGFG1 acts as a sponge of miR-195-5p to promote triple-negative breast cancer progression through regulating CCNE1 expression. Molecular Cancer 18 4. (https://doi.org/10.1186/s12943-018-0933-7)

Yates LA, Norbury CJ \& Gilbert RJ 2013 The long and short of microRNA. Cell 153 516-519. (https://doi.org/10.1016/j. cell.2013.04.003)

You X, Vlatkovic I, Babic A, Will T, Epstein I, Tushev G, Akbalik G, Wang M, Glock C, Quedenau C, et al. 2015 Neural circular RNAs are derived from synaptic genes and regulated by development and plasticity. Nature Neuroscience 18 603-610. (https://doi.org/10.1038/ nn.3975)
Yu J, Xu QG, Wang ZG, Yang Y, Zhang L, Ma JZ, Sun SH, Yang F \& Zhou WP 2018 Circular RNA cSMARCA5 inhibits growth and metastasis in hepatocellular carcinoma. Journal of Hepatology 68 1214-1227. (https://doi.org/10.1016/j.jhep.2018.01.012)

Yuan B, Song Y, Sheng Y, Zheng K, Huo Q, Xu X \& Zou H 2016 Luminescence and energy-transfer properties of color-tunable Ca2Mg0.25Al1.5Si1.25O7:Ce(3+)/Eu(2+)/Tb(3+) phosphors for ultraviolet light-emitting diodes. Luminescence 31 453-461. (https:// doi.org/10.1002/bio.2981)

Yuan W, Zhou R, Wang J, Han J, Yang X, Yu H, Lu H, Zhang X, Li P, Tao J, et al. 2019 Circular RNA Cdr1as sensitizes bladder cancer to cisplatin by upregulating APAF1 expression through miR-1270 inhibition. Molecular Oncology 13 1559-1576. (https://doi. org/10.1002/1878-0261.12523)

Zeng K, He B, Yang BB, Xu T, Chen X, Xu M, Liu X, Sun H, Pan Y \& Wang S 2018 The pro-metastasis effect of circANKS1B in breast cancer. Molecular Cancer 17 160. (https://doi.org/10.1186/s12943-018-0914-x)

Zhang L, Zhang X, Zhang X, Lu Y, Li L \& Cui S 2017a miRNA-143 mediates the proliferative signaling pathway of FSH and regulates estradiol production. Journal of Endocrinology 234 1-14. (https://doi. org/10.1530/JOE-16-0488)

Zhang X, Zhang X, Hu S, Zheng M, Zhang J, Zhao J, Zhang X, Yan B, Jia L, Zhao J, et al. $2017 b$ Identification of miRNA-7 by genomewide analysis as a critical sensitizer for TRAIL-induced apoptosis in glioblastoma cells. Nucleic Acids Research 45 5930-5944. (https://doi. org/10.1093/nar/gkx317)

Zhang L, Zhou Q, Qiu Q, Hou L, Wu M, Li J, Li X, Lu B, Cheng X, Liu $\mathrm{P}$, et al. 2019a circPLEKHM3 acts as a tumor suppressor through regulation of the miR-9/BRCA1/DNAJB6/KLF4/AKT1 axis in ovarian cancer. Molecular Cancer 18 144. (https://doi.org/10.1186/s12943019-1080-5)

Zhang S, Liao K, Miao Z, Wang Q, Miao Y, Guo Z, Qiu Y, Chen B, Ren L, Wei $Z$, et al. $2019 \mathrm{~b}$ circFOXO3 promotes glioblastoma progression by acting as a competing endogenous RNA for NFAT5. Neuro-Oncology 21 1284-1296. (https://doi.org/10.1093/neuonc/noz128)

Zhang X, Wang S, Wang H, Cao J, Huang X, Chen Z, Xu P, Sun G, Xu J, Lv J, et al. 2019c Circular RNA circNRIP1 acts as a microRNA-149-5p sponge to promote gastric cancer progression via the AKT1/mTOR pathway. Molecular Cancer 18 20. (https://doi.org/10.1186/s12943018-0935-5)

Zhao ZJ \& Shen J 2017 Circular RNA participates in the carcinogenesis and the malignant behavior of cancer. RNA Biology 14 514-521. (https://doi.org/10.1080/15476286.2015.1122162)

Zhen N, Gu S, Ma J, Zhu J, Yin M, Xu M, Wang J, Huang N, Cui Z, Bian Z, et al. 2019 circHMGCS1 promotes hepatoblastoma cell proliferation by regulating the IGF signaling pathway and glutaminolysis. Theranostics 9 900-919. (https://doi.org/10.7150/ thno.29515)

Zhong Z, Huang M, Lv M, He Y, Duan C, Zhang L \& Chen J 2017 Circular RNA MYLK as a competing endogenous RNA promotes bladder cancer progression through modulating VEGFA/VEGFR2 signaling pathway. Cancer Letters 403 305-317. (https://doi. org/10.1016/j.canlet.2017.06.027)

Zhou S, Jiang H, Li M, Wu P, Sun L, Liu Y, Zhu K, Zhang B, Sun G, Cao C, et al. 2019 Circular RNA hsa_circ_0016070 is associated with pulmonary arterial hypertension by promoting PASMC proliferation. Molecular Therapy: Nucleic Acids 18 275-284. (https://doi. org/10.1016/j.omtn.2019.08.026)

Zhu Y, Pan W, Yang T, Meng X, Jiang Z, Tao L \& Wang L 2019 Upregulation of circular RNA circNFIB attenuates cardiac fibrosis by sponging miR-433. Frontiers in Genetics 10 564. (https://doi. org/10.3389/fgene.2019.00564)

Received in final form 14 July 2020

Accepted 3 September 2020

Accepted Manuscript published online 4 September 2020 (c) 2020 Society for Endocrinology Published by Bioscientifica Ltd. Printed in Great Britain 